\title{
PSYCHOLOGICAL PROVISION OF ACTIVITIES OF PROFESSIONALS IN THE CONDITIONS OF METALLURGICAL PRODUCTION
}

\author{
Sheviakov O. V., Shramko I. A.
}

\section{INTRODUCTION}

Difficult and strenuous conditions of the operator's / metallurgist's activity demand a due approach to the whole man-machine system optimization. This approach must consider all the operator's activity features (psychological ones first) and include appropriate research methods and ergonomic planning ones.

The consideration of psychological factors in the development of new technical means of activity and modernization of the available ones is an indispensable condition to realize their economic efficiency.

The methodological basis of the research was G. Zarakovsky's ergonomic providing concept of the men-machine system development and exploitation ${ }^{1}$.

The problem of increasing the efficiency of the "Rolling-Mill" manmachine system operating isn't new. As a result of the analysis of some theories which concern rolling-mill operator's activities and were published in different time researches, we can distinguish some real-life approaches to the issue. A technological approach is aimed at the local automatization and the commitment of the rolling mill during a shift as well as at the idle times of the rolling mill and their reasons. A sanitary and hygienic one is aimed at the assessment of the complexity and tension in rolling-mill operator's activity. And an ergonomic approach is mostly reduced to the rationalization of control panels and organization of work stations. Foreign researchers define technology features and the level of management automation as the external determinants of psychological tension and stressful factors in the activity of metallurgical unit operators. An analysis of modern foreign ergonomic and psychological literature revealed the presence of theoretical assumptions of the operator's activity optimization in different countries. The ergonomic direction of metallurgists' activity optimization, which developed fragmentary in Ukraine and China, continues our research.

${ }^{1}$ Zarakovsky G. The concept of theoretical evaluation of operators' performance derived from activity theory. Theoretical Issues in Ergonomics Science. 2014. Vol. 5. P. 313-337. 
Operators of continuous broad band rolling mills have been examined in two countries. The research was conducted under production conditions of the Dnipro Metallurgical Plant and the "Buncy Steel" Steel Mill, which have a cooperation agreement among themselves ${ }^{2}$.

The subject of the research was an ergonomic provision of optimization of rolling-mill operators' activity and its correlation with the production efficiency of socio-technical systems (see the figure). The psychological, physiological and psychophysiological factors of intensification of metallurgical production technological processes were studied.

The purpose of the research is to define the influence features of ergonomic and psychological factors on the activity efficiency of continuous broadband rolling mill operators in the conditions of metallurgical enterprises modernization of the two countries.

The aim of the article is to present the results of the influence features of ergonomic and psychological factors on the activity efficiency of continuous broadband rolling mill operators in the conditions of metallurgical enterprises modernization of the two countries.

\section{Materials and methods}

The first group of methods contains a traditional job analysis including observations, interviews and conversations with experts; an analysis of fabrication documentation and official instructions and regulations; an identification of metal processing mode violations by operators, emergency situations and production idle times. The age of operators, their sex and length of service were recorded.

The survey was carried out to determine the subjective attitude of operators toward the objective factors of technological process modernization, which affect upon the occupational stress and psychological tension occurring in the workplace, and to identify the main motivational aspects of operator's activity.

An algorithmic analysis of the operators' activity was based on the observation and examination of the fabrication documentation. A control algorithm analysis on the rolling mills of the same type of ingots was carried out according to the standard compression program. The purpose of the analysis was to compare quantitative characteristics of the operator's activity on the control of the main electric drive and the associated machinery ${ }^{3}$.

2 URL: http://project.ukrinform.ua/company/dniprovskyi_ metalurgiinyi_kombinat_ 64696.

${ }^{3}$ Bedny G. Activity theory: history, research and application. Theoretical Issues in Ergonomics Science. 2010. Vol. 2. P. 168-206. 
We haven't only used the algorithm characteristics to estimate the cognitive complexity of the algorithm. The data obtained as a result of the operators' activities analysis were also considered. The heart rate (HR) and adjusted hand tremor data were used to assess the dynamics of the operator functional state. The dynamics of the heart rates was considered in the research as an integral characteristic of the functional tension of the organism in productive work, which is followed by psychoemotional excitement.

The heart rate measurement was carried by electrocardiography. The frequency of hand tremor was measured by a digital thermometer.

Hand dynamometry was used as an indicator of operators' fatigue.

A group of psychological techniques was aimed to analyze the impact of professional activity on operators mental functions connected with receiving, processing, storage and playback of information. Some methods of studying memory, attention and processes of thinking were used to investigate the commitment of the mental functions. Memorization of numbers and their further reproduction were used to study memory.

Tables and proofreading tests were used to study attention levels. Characteristics of distribution (d) and concentration (co) of attention were determined.

A concentration level was calculated due to the proof tests by the formula 1:

$$
X_{\mathrm{co}}=(0,5436 \cdot N-2.807 \cdot n) / T
$$

Xco - the level of attention concentration (information processing rate, $\mathrm{bit} / \mathrm{s})$;

$\mathrm{N}$ - the number of proofreading test signs seen for an hour T;

$\mathrm{n}$ - the number of missed or mistakenly crossed out signs for an hour T.

The distribution of attention was estimated by the operating time (To) with the first ten pairs of numbers from the black and red table. The

quantity, where $\mathrm{k}_{d}$ is the normalizing coefficient, was used to characterize the distribution of attention $(\mathrm{Xd})$.

The time of the row numbers addition (Tth) was used to estimate the indicators of thinking in the formula $2^{4}$. It was determined as asum of the time for the task solution (Tthp) and the "penal" one (Tthp), which was equal to the difference module of the received result $(\mathrm{Cr})$ from the addition of simple quantities of the proposed election numbers and the actual value $(\mathrm{Ca})$,

${ }^{4}$ Brito J. About women and work: towards the construction of a female work ergonomics. Designing for everyone. L. : Taylor and Francis, 2011. P. 17-22. 


$$
\mathrm{T}_{\mathrm{thp}}=\left|\mathrm{C}_{r}-\mathrm{C}_{a}\right|
$$

The quantity with the normalizing coefficient Kth $=100$ s was used as the indicator of thinking. The characteristic of memory $(\mathrm{Xm})$ was defined in points as $\mathrm{Xm}=5-\mathrm{q}$, where $\mathrm{q}$ is the quantity of mistakes and number permutations at the reproduction of the remembered number.

Reactive anxiety (RA) and personal anxiety (PA) were determined by the Charles Spielberger and Yuri Hanin's self-rating research technique.

The following sequence of testing was applied: cardiography, tremorometry, dynamometry, number memorization (15 seconds of showing), proofreading test, red and black table, number reproduction.

The total operating time of each mentioned methods allowed carrying out workplace examinations. A special expert survey was used to assess the quality of the work. The operators' activities were estimated by the experts on seven parameters - efficiency of the activity, fulfillment of the process requirements and processing programs, quality of the in got production, quantity of the mistakes made while the activity, coordination measure of control functions in the operator's activity, control character of rolling mill drives and operator's attitude to the assigned work. The first six parameters describe operator's professional skills. And, together with the seventh one, they characterize the operator's input in the production process. The experts were a production supervisor, a shift engineer, a rolling mill deputy manager and three of the most experienced operator-instructors. The professional activity of each operator was estimated by nine experts. The consistency of the expert evaluations was checked.

Lusher test was used to study aspects of the functional state of rolling mill operators and their attitude to the factors of modernized metallurgical production $^{5}$.

All of these methods were adapted in accordance with the professional analysis rules of rolling mill operators activities analog systems and prototypes.

Two hundred rolling mill operators from Ukraine and China took part in the research. In other words, one hundred men and women at the age from 17 till 46 years old were taken from each county. They were compared by the age and gender parameters.

Traditional methods of mathematical statistics in the interpretation by were used to process the results.

\footnotetext{
${ }^{5}$ Chapanis A. Researcg techniques in human engineering. Baltimore : J. Hopkins University Press, 2012. P. 121-125. 


\section{Results}

A decomposition of the socio-technical management system to subordinate sub systems with a systemically important role of active operators' activities was carried out and the activity complexity was estimated.

The complexity assessment indicators of control algorithms during one rolling cycle are given in the Table 1 .

Among the key factors, that determine the complexity and intensity of professional activities, operators distinguish organizational and technological ones. The operators of the most productive and newer mill of the "Buncy Steel" Metallurgical Complex in China evaluate the occupational stress higher than Ukrainian rolling mill operators.

We should note the higher liability of differences in the all mill operator's assessments of the operational tension and the degree of influence on the activity of technological and organizational production factors $(p<0,01)$. Some significant differences in operators' assessments of the cognitive component of occupational stress and the influence of the technological production factors were found (at $p<0,05$ ).

Table 1

Ergonomic Assessment of the Control Algorithms Complexity of Operators' Activities

\begin{tabular}{|c|c|c|c|c|c|c|c|}
\hline $\begin{array}{c}\text { Rolling } \\
\text { Mill }\end{array}$ & $\mathbf{N}$ & $\mathbf{N} l$ & Va & Kns & $\mathbf{K} n l$ & $\mathrm{Cv}$ & $\mathbf{S} \boldsymbol{k}$ \\
\hline Ukraine & 166 & 76 & 3,9 & 0,4 & 0,2 & 0,16 & 0,25 \\
\hline China & 246 & 92 & 5,8 & 0,4 & 0,2 & 0,12 & 0,30 \\
\hline \multicolumn{8}{|c|}{$\begin{array}{l}\text { Notation: } \mathrm{N}-\text { the total number of algorithm parts; } \mathrm{N} l-\text { the number of logical } \\
\text { conditions; } \mathrm{V} a-\text { the tension of the algorithm realization (the number of } \\
\text { operations per second); Kns i K } n l-\text { the standardized coefficients of stereotype } \\
\text { and logical complexity of the operator's activity; } \mathrm{C} v-\text { the coefficient of } \\
\text { variation of movements per one rolling cycle; } \mathrm{S} k-\text { the coefficient of cognitive } \\
\text { complexity of the algorithm. }\end{array}$} \\
\hline
\end{tabular}

Chief operators feel the influence of social and psychological factors on their professional activities more than manipulator operators. Job satisfaction and the assessment of labor importance increase with the improvement of the operators`skills.

In the analysis of the information exchange between operators and the rolling technological process, which was controlled by the complex of technical devices, it was discovered that the variation in the number of movements of the chief operators during one rolling cycle was $16 \%$ in Ukraine and $12 \%$ in China at relatively stable time of ingot rolling (the coefficient of variation was $2,8 \%$ for the rolling mill in Ukraine, 3,5\% and 5,2\% for the mill in China). The variation 
for the manipulator operators are correspondingly $26 \%$ and $21 \%$. A comparative analysis of the operators' load in the control of individual machines was carried out in order to identify the causes of stochastic activities. It turned out that the control of the main drive makes on average $37 \%$ of the chief operators' movements during one rolling cycle (5\% in Ukraine and 39\% in China). The control of the pressure device makes $26 \%$ of the movements (28\% in Ukraine and $25 \%$ in China). The control of the front table makes $17 \%$ (20\% in Ukraine and $14 \%$ in China) and the rear mill one makes $11 \%$ (10\% in Ukraine and $12 \%$ in China).

The intensity of operator's activity is characterized by the intensity indicators of control element movements (per second) and the variability of the movements for an in got processing stage (as a percentage) ${ }^{6}$. It is possible to stipulate that a motor stereotype of operators is characterized by the movement intensity of the control elements, which is measured by the coefficient of variation. It makes sense to talk about an active "adaptation" of operators to the activity process. The received average indicators are given in the Table 2 .

The confirmation of the operators' active "adaptation" to their psychophysiological features is the increase of the variable component (by 6 times) of the ingot processing time and the number of movements (by 3 times) in the same pass.

Table 2

Movement Intensity of the Control Elements and the Operators' Movement Variability

\begin{tabular}{|c|c|c|c|}
\hline \multicolumn{2}{|c|}{ Operators } & \multicolumn{2}{c|}{ Rolling Mill } \\
\cline { 2 - 4 } & China & Ukraine \\
\hline \multirow{2}{*}{$\begin{array}{c}\text { Chief } \\
\text { Operators }\end{array}$} & $\begin{array}{c}\text { The movement intensity } \\
\text { of the control elements, } \\
\text { movement / second }\end{array}$ & 2,9 & 2,7 \\
\cline { 2 - 4 } & Movement variability, \% & 27,0 & 28,0 \\
\hline \multirow{2}{*}{$\begin{array}{c}\text { Manipulator } \\
\text { Operators }\end{array}$} & $\begin{array}{c}\text { The movement intensity } \\
\text { of the control elements, } \\
\text { movement / second }\end{array}$ & 2,1 & 2,8 \\
\cline { 2 - 4 } & Movement variability, \% & 23,0 & 27,0 \\
\hline
\end{tabular}

The average coefficients of variation are given in the Table 3 as the tension indicators of psychophysiological and psychological functions of the rolling mill operators. The range of the variation coefficients from $10 \%$ to $20 \%$ corresponds to the average psychological tension. If it is more than

\footnotetext{
${ }^{6}$ Foley J. Fundamentals of Interactive Computer Graphics. Reading : Addisson Wesley, 2014. P. 73-86. 
$20 \%$, the tension is high. If the range of the variation coefficients is less than $10 \%$, the tension is low. The indicators, which characterize the intensity of heart rate (HR), tremor, concentration and attention al resource allocation, memory and thinking, are also given in the table.

ThecomparisonoftheHRintensityoftherollingmilloperatorsintwocountries showedthat the occupational activities of the chief rolling mill operators from China were more intense than the ones of the chief operators from Ukraine. The requirements of the attention al resource allocation on a significant number of controlled mechanisms and the concentration of attention (which was increased by the attention slippage) are confirmed by the tension indicators of psychical functions.

Table 3

Variation Coefficients (\%) of Psychical and Physiological Functions Indicators of the Rolling Mill Operators

\begin{tabular}{|c|c|c|c|c|}
\hline \multirow{2}{*}{ Functions } & \multicolumn{2}{|c|}{ Manipulator Operators } & \multicolumn{2}{c|}{ Chief Operators } \\
\cline { 2 - 5 } & Ukraine & China & Ukraine & China \\
\hline $\begin{array}{c}\text { Concentration } \\
\text { of Attention }\end{array}$ & $19,9 \pm 7,5$ & $16,8 \pm 8,5$ & $23,0 \pm 5,5$ & $17,8 \pm 9,6$ \\
\hline $\begin{array}{c}\text { Attentional } \\
\text { Resource } \\
\text { Allocation }\end{array}$ & $17,5 \pm 9,0$ & $24,2 \pm 11,8$ & $21,3 \pm 7,0$ & $36,1 \pm 9,8$ \\
\hline Memory & $40,4 \pm 24,1$ & $31,7 \pm 23,6$ & $33,6 \pm 23,1$ & $37,1 \pm 25,8$ \\
\hline Thinking & $12,5 \pm 7,2$ & $12,5 \pm 8,5$ & $12,9 \pm 4,9$ & $14,1 \pm 7,0$ \\
\hline Tremor & $37,5 \pm 16,9$ & $40,0 \pm 17,8$ & $33,1 \pm 12,6$ & $38,2 \pm 6,9$ \\
\hline $\begin{array}{c}\text { Heart Rate } \\
\text { Intensity }\end{array}$ & $6,9 \pm 4,4$ & $7,8 \pm 3,3$ & $8,1 \pm 4,9$ & $5,8 \pm 1,9$ \\
\hline
\end{tabular}

According to the Tables 3 and 4, the attention resource allocation of the Chinese operators prevails over their concentration of attention. But in Ukraine the concentration of attention of the rolling mill operators, who had to recognize a slippage of the rolls on the basis of visual information from the functional area, prevails over the distribution of attention. Thus, the control systems of rolling mill analogues are specific.

The psychological analysis of the operators' activities is confirmed by the research results of short-term memory tension. Chief operators in China have to memorize 26 press round programs (14 ones in Ukraine), the implementation of which is carried out by the predetermined position of the rolls in each of the 14 spaces. And it leads to the tension of short-term memory. On the other hand, a more difficult calibration of the mill rolls in Ukraine (that contains 5 roll passes against 4 ones for a Chinese roll mill) leads to the increase of the manipulator operators' contribution to the realization of the press round programs, which put an ingot against one of 
the set roll passes. As a result, the memory tension of the Ukrainian manipulator operators dominates over the tension of this psychical function of the manipulator operators in China.

Table 4

Psychical Functions Indicators of the Rolling Mill Operators ( $\mathbf{M} \pm \mathbf{m}$ )

\begin{tabular}{|c|c|c|c|c|}
\hline \multirow{2}{*}{ Functions } & \multicolumn{2}{|c|}{ Manipulator Operators } & \multicolumn{2}{c|}{ Chief Operators } \\
\cline { 2 - 5 } & Ukraine & China & Ukraine & China \\
\hline $\begin{array}{c}\text { Concentration } \\
\text { of Attention }\end{array}$ & $11,4 \pm 0,1$ & $11,2 \pm 0,2$ & $11,2 \pm 0,2$ & $21,5 \pm 0,2$ \\
\hline $\begin{array}{c}\text { Attentional } \\
\text { Resource } \\
\text { Allocation }\end{array}$ & $11,6 \pm 2,0$ & $13,1 \pm 2,1$ & $13,1 \pm 2,1$ & $13,9 \pm 1,6$ \\
\hline Memory & $5,0 \pm 1,0$ & $4,1 \pm 0,9$ & $4,1 \pm 0,9$ & $4,8 \pm 0,6$ \\
\hline Thinking & $30,7 \pm 7,8$ & $31,6 \pm 5,5$ & $31,6 \pm 5,5$ & $33,0 \pm 8,0$ \\
\hline State Anxiety & $41 \pm 4$ & $40 \pm 2$ & $40 \pm 2$ & $35 \pm 7$ \\
\hline Trait Anxiety & $42 \pm 3$ & $40 \pm 3$ & $40 \pm 3$ & $38 \pm 5$ \\
\hline Age & $31 \pm 5$ & $32 \pm 6$ & $32 \pm 6$ & $35 \pm 3$ \\
\hline Gender & $10 \pm 2$ & $11 \pm 3$ & $11 \pm 3$ & $11 \pm 2$ \\
\hline
\end{tabular}

The psychological factors research has determined a negative impact of the following indicators on the characteristics of the operators' activities. They are: 1) a supply rhythm of ingots from the reheating furnaces; 2) a quality of their heating and a scale crust presence; 3 ) a timely removal of ingots from the heating area, work rhythm and accident-free operations ${ }^{7}$.

The analysis of the psychophysiological parameters of operators' activities allows to trace the dynamics of fatigue development as well as to establish a connection between the reality and mental health, which accompanies their activities. The Table 5 shows the operators' heart rate changes depending on the performed functions.

Table 5

\section{Rolling Mill Operator's Heart Rate (M $\pm \mathbf{m})$}

\begin{tabular}{|c|c|c|c|c|}
\hline \multirow{2}{*}{ Heart Rate } & \multicolumn{2}{|c|}{ Manipulator Operators } & \multicolumn{2}{c|}{ Chief Operators } \\
\cline { 2 - 5 } & Ukraine & China & Ukraine & China \\
\hline $\begin{array}{c}\text { After an hour } \\
\text { of work }\end{array}$ & $75,7 \pm 11,7$ & $85,1 \pm 10,9$ & $85,1 \pm 10,9$ & $75,9 \pm 15,1$ \\
\hline $\begin{array}{c}\text { After an hour } \\
\text { of rest }\end{array}$ & $79,5 \pm 10,4$ & $82,3 \pm 11,5$ & $82,3 \pm 11,5$ & $73,3 \pm 5,5$ \\
\hline
\end{tabular}

${ }^{7}$ Thu G. The bases of psychology intensification of high-automatical processes under the condition of metalical production (for instance Ukraine, Russia and China). Experimentele Psichologie : Abstractder 45 Tagung experimentell arbeiten der Psychologen. Kiel. 2013. P. 211. 
According to the table we can see that the operators' transition to active actions on the control of the mill main drive leads to the increase in the heart rate on average by 5\%. A level of the heart rate at the end of the pause doesn't apparently reflect a rest state but shows the measure of the preventive innervation which is expressed in the strengthening of physiological processes and thus promotes their course in the labor hours. The HR decrease of the Ukrainian manipulator operators (on average by 7\%) speaks about the monotonous nature of their work. The latest data are consistent with the stereotype indicators and logical complexity of algorithms, which are given in the Table 1 and confirm the validity of conclusions.

The transition from one press round program to another does not change the stereotype and rhythm of the operators activities. This is due to the fact that the nature of the operations remains invariable and only their sequence changes. The psychophysiological functions confirm that a press round program change doesn't affect the heart rate and tremor. Thus, a change of the rolling program doesn't cause any tension emotions or maintenance level changes of the cardiovascular system of the operators.

The impact of the sudden changes in characteristics of the activity methods (rolling mill electric drive), the indicator of which is an increase in the heart rate, on the psychophysiological functions is more pronounced. It confirms the leading role of the activity methods as an ergonomic factor that affects on the functional state of the operators. This is especially true for the Ukrainian rolling mills due to a greater (in comparison with the Chinese mills) modernization of the activities nature of the chief operators during the changes in the workplaces. First of all, these changes concern an information aspect of the activities. A comparison of the algorithms complexity of the operators activities shows that the complexity of the activity algorithms of the Ukrainian chief operators is 2,5 times more than the control algorithm variable of the similar properties for the manipulator operators. A comparison of these indicators gives the value of 1,5 for the Chinese mills. The subjective assessment of the cognitive component of the operators' occupational loading, which was made by the chief rolling mill operators in Ukraine, is on average 1,2 times higher than the assessment made by the manipulator operators. The HR dynamics of the chief operators confirms the reduction of the burden on the cardiovascular system while the performance of the manipulator operator's duties.

The dynamics of the mental functions leads to the conclusion about the greatest stability of the attention resource allocation function and the short term memory one during a shift. The execution time of the black and red table test in most cases tends to decrease. We interpret this fact in the following way. The most important psychical function for work remains to ensure the optimum efficiency of the operator's occupational activity, including due to the stress of the other body function systems. 
As a result of the analysis of labor efficiency by the criterion, which connects the productivity and energy consumption, all the examined rolling mill operators from Ukraine and China have been conditionally divided into three groups: 1) the most "successful" in the occupational activities; 2) the operators with an average "success"; 3 ) the "least successful" operators.

The psychological indicator values differentiated according to the professional success of the chief operators are given in the Table 6 .

It was found that the most "successful" operators had the highest social and labor activity with a high index of satisfaction with their job. The operators from the third group of professional success are characterized by low social and labor activity. They estimate inadequately their occupational loading and underestimate the influence of the organizational factors of metallurgical production.

The level of claims is reflected in the assessment of the labor importance. It is also revealed in the reduction of satisfaction of the operators from this group with their own activities in the conditions of a low objective estimation of the labor results. We found an increase of the anxiety level among the "most successful" and the "least successful" operators. It can be explained as follows: the anxiety level of the first group operators increases due to the mobilization of the activities and the anxiety level of the third group operators increases because of the non-optimality of the activities, inadequate self-esteem and lack of the occupational adaptation.

We have established a satisfactory validity for the most used methods (not lower than 0,7 ).

Table 6

Operators' Condition in Groups with Different Professional Success $(\mathbf{M} \pm \mathbf{m})$

\begin{tabular}{|c|c|c|c|}
\hline \multirow{2}{*}{ Indicators } & \multicolumn{3}{|c|}{ Professional Success Group } \\
\cline { 2 - 4 } & $\begin{array}{c}\text { The } \mathbf{1}^{\text {st }} \text { (the most } \\
\text { successful) }\end{array}$ & $\begin{array}{c}\text { The 2 } \\
\text { average success) }\end{array}$ & $\begin{array}{c}\text { The } 3^{\text {rd }} \text { (the } \\
\text { aveast successful) }\end{array}$ \\
\hline Age & $45,5 \pm 7,0$ & $42,0 \pm 5,2$ & $36,5 \pm 10,5$ \\
\hline Length of Service & $18,0 \pm 9,5$ & $15,5 \pm 7,5$ & $12,5 \pm 10,0$ \\
\hline State Anxiety & $43,0 \pm 0,5$ & $35,5 \pm 7,5$ & $39,5 \pm 2,5$ \\
\hline Trait Anxiety & $42,5 \pm 6,5$ & $38,5 \pm 5,5$ & $37,5 \pm 8,5$ \\
\hline Heart Rate & $95,5 \pm 15,5$ & $82,5 \pm 8,5$ & $85,5 \pm 15,3$ \\
\hline $\begin{array}{c}\text { Expert } \\
\text { Assessment }\end{array}$ & $89,0 \pm 2,5$ & $95,5 \pm 3,5$ & $75,3 \pm 5,0$ \\
\hline $\begin{array}{c}\text { Social and Labor } \\
\text { Activity }\end{array}$ & $14,5 \pm 3,5$ & $15,5 \pm 2,5$ & $12,5 \pm 2,3$ \\
\hline Job Satisfaction & $75,3 \pm 15,8$ & $75,5 \pm 17,4$ & $55,5 \pm 15,1$ \\
\hline $\begin{array}{c}\text { Occupational } \\
\text { Loading }\end{array}$ & $65,6 \pm 5,2$ & $63,6 \pm 4,7$ & $64,5 \pm 4,5$ \\
\hline Labor Importance & $85,8 \pm 5,7$ & $75,0 \pm 9,5$ & $83,2 \pm 4,3$ \\
\hline
\end{tabular}


We cannot ignore a person's attitude to the activity in the study of psychological factors of the rolling mill operators' activities. It is also impossible to solve any optimization problems of the operators' activities excluding these factors.

The color-association method usage allowed revealing deep and extra mental interaction components in a number of important factors and at the same time passing the protective mechanisms of the verbal system of consciousness.

Thus, having limited the own research sphere of emotional aspects by the psychological analysis frameworks of the operators' professional activities and mental processes and states, which accompany these activities, we consider emotions on the one hand as an indicator of the operator's functional condition in the activity and on the other hand as an indicator of the specialist's attitude to his job and a set of production factors.

A set of colored stimulus - response reactions of the Lusher's test, which were presented by eight cards, was used as the research device.

The tasks of the color-association research were formulated as follows:

1) to analyze the possibilities of psychological diagnostics of the operator's functional condition in the activity and his correlation with professional success by means of the Lusher test (the basis for the analysis is the premise of the psychological theory of activity about the reflection of the individual states in emotions);

2) to consider the possibilities of the color-association method usage for the diagnostics of the operators' attitudes to their activities and the manufacturing and technological environment (the basis is the premise of the psychological theory of activity about the reflection of the person's states and his attitude to the world and own activities in emotions);

3) to consider the possibilities of the color-association method usage for the diagnostics of the interpersonal relations of the operators and to analyze their influence on the teamwork efficiency (the basis for the analysis is the premise of the psychological theory of activity about the reflection of the attitude of one person to an other in emotions).

The solving of the first task is connected with a traditional usage of the Lusher test. A frequent repetition of the each operator testing during a shift allowed revealing the changes dynamics of the emotional states.

Compliance between all the mental properties and indicators was traced in the quantitative interpretation of the Lusher test. At the same time heteronomy and autonomy indicators of the Lusher test correspond to the mood swing indicators and the emotional stability ones as well as the indicators of eccentricity and concentricity correspond to the excentrality and internality. Shiposh vegetative coefficient and a method of measuring the size of the color elections deviation from the "Autogenic norm" (AT- 
norms) were used. The size of the total deviation from the AT-norm is connected with the rigidity of requirements which is moved forward to a work performer by the specificity of the profession.

The second task that has been solved due to the Lusher testing connected closely with the functional state diagnostics. But in addition to the above an emphasis on the reflection of the subject's attitude toward reality in emotions, which characterize the human condition is dominate. Thus, we proceeded from the assumption, according to which the human condition that is formed and shown in his activity is associated with an indicator of adaptation in the production process and also is the function of the specialist's attitude to his occupational activity.

During the study process of the operators' attitude character to their activities, the operators were offered to grade an eight color card in reference to the concept "what is emotionally considerable for a specialist operator". The question was as follows: "What is the color of your work?" It was provided that human disadaptation in the conditions of the professional environment is shown in a mismatch of the "personal" card components of the Lusher test as the characteristics of the operator's functional state and the eight color card, which is associated with the subject's attitude to his own activity.

The quantitative mismatch is defined as a difference of the corresponding interpretative coefficients which were calculated for the both cards. The mismatch is psychologically interpreted as a measure of deviation of the specialist's personal characteristics from the emotional and conceptual image of the production environment and operator's own activities in it.

The third task that was solved due to the color association method is connected with a necessity to analyze the influence of the operators' interpersonal relationships, which are formed in the course of their professional engagement, on the labor efficiency and functional state. The traditional sociometric research methods of interpersonal relationships in small groups are ineffective. The usage of the sociometric assessments on the basis of a partner choice is shoved against the "psychological barrier" at the rolling mill operators. We explain it by the specificity of the studied contingent and activity features: constant contingent of rolling mill operators 9 about 30-40 people) because of the high complexity of the activities; longterm collaboration; clear system of the internal hierarchy; segregation of the operators' duties, which is as close as possible to the functional segregation; limited communication by the teamwork conditions.

There are three variants of the operators' answers in the sociometric surveys, which were conducted in a verbal form: positive attitude to the all colleagues that is not differentiated; positive attitude to the members of the own control post and refusal to assess own attitude; evasion of the attitude 
assessment to the colleagues. However, a negative attitude to the teamwork with some operators because of personal reasons was noted in private conversations. Thus, the task solution of the collectives forming according to the conditions of not only the highest teamwork efficiency, but also a positive emotional background of interpersonal relationships is one of the necessary conditions of the operator's activity optimization.

The usage of the color association method for the solution of the pointed task is based on the provision that people associate the colors naturally and statistically significantly with their emotional and personal characteristics. The emotional characteristics, which were defined by the Lusher test, are connected with deep attitudes of the person that are significant for the interpersonal interaction process of the collective subject of activity.

The analysis of the comparison of production efficiency of the operators' activities and their professional characteristics leads to the conclusion about an influence of motivational aspects and personal factors on the workers' professional success.

It was found that the operators" "eccentricity", "autonomy" and "working capacity" decrease in the course of the deterioration of their professional success, reduction of the social and labor activity and a positive expert evaluation of their work by the management. At the same time the indicators of "concentricity", "heteronomy" and "stress" grow; and the attitude to the activities worsens.

The interpretation of the test results leads to a conclusion that the most successful operators in their professional attitudes are characterized by an active orientation on the professional environment in terms of the impact on it as well as by the high self-control, independence and person's balance, and lack of the person's retardation.

The third (worst) group of operators is characterized by the increased dependence on the environment, sensitivity to the effects of it and passivity, by the propensity for the defensive reactions, external accusatorial direction in reactions to frustration and personal contradictions. The second group of operators is intermediate according to the production indicators and the "personal" ones.

The analysis of the color -association test results showed the smallest two color card divergence in the indicators of "eccentricity" and "personality balance" in the most successful group and in the indicators of "anatomy" in the second and the third groups of the operators.

The "most successful" specialists-operators have the slightest deviation from the "Autogenic norm" as well as the smallest deviation of the coefficients in the Lusher test "personal" card. In general, a tendency of the value approximation of the color row interpretative coefficients to the corresponding indicators of the Lusher "personal" card, which are distinctive 
for the successful operators, is observed for the operators of the worst professional success group. The adequate to the production environment operators' "understanding" of the necessary personal qualities causing the efficiency of activities is reflected in it.

At the same time a tendency to the unproductive decrease of the "eccentricity" indicator in the color-association test in comparison with the similar indicator of the Lusher test is noted for the "unsuccessful" operators. The low "concentricity" indicator of the third group specialists (in comparison with the ones from the first group) as well as the labor efficiency underestimation of this indicator is interpreted as a reduction of the creative activity in this group of operators, an absence of the expressed addiction to the environment (working conditions) changes according to the specific features and requirements. The low level of these operators' social and labor activities and the low operators' assessment of the organizational ergonomic factors influence on the occupational loading can provide an "optimizing" effect in conditions of the active realization of their personal positions in the collective.

\section{CONCLUSIONS}

A comparison of the labor efficiency of the rolling mill operators and their psychological characteristics leads to the conclusion about the existence of a nonrandom influence of the motivational aspects and personal factors on the personnel professional "success". An ergonomic assessment of the operator's activities proved that the rolling mills modernization requires the consideration of psychological factors (difficulty and intensity of activities, functional states of specialists) in the development of technological modes (press round programs) and in the creation of local and integrated automation systems, in the improving process of the organizational and information support for the operator's activity during the exploitation of the socio-technical system. The level of metallurgical production organization is shown in such indicators of the functioning of rolling mills as efficiency, rhythm, continuity and capacity and has an impact on the social and psychological status of a specialist, psychological climate in the collective and job satisfaction. The subjective qualities of operators (social and labor activity, job satisfaction and labor importance) influence on the success of the professional activities and functional states. In such a case, the motivation level, attitudes to the activities and social and labor activity have a great importance. It is necessary to take into account not only technical factors, but also psychological features of the specialists in the selection and arrangement of the rolling mill operators personnel of new generations in both countries. In China the problem of selection and arrangement of specialists-operators should be considered on the aspect of 
providing psychological aid to conscientious workers in the usage of their own psychological resources with maximum efficiency due to the existed in China national adjustments for the provision of personal labor efficiency. In Ukraine the requirement of the unconscionable workers identification is added to this aspect of the problem as well as the incompetent workers identification. The research methodical complex of the professionally important operators` psychological qualities (occupational attention, short term memory and thinking) can be used for the professional selection of operators and their further vocational training. The prospects of similar ergonomic studies are seen in the creation of the psychological and ergonomic theory of a functioning intensification of the metallurgical production high-automated processing, which can be a competitive advantage in terms of socio-economic crisis.

\section{SUMMARY}

The article presents the results of processes ergonomic modernization of metallurgical production management were discussed in two countries under new economic (market) conditions. The factors, which define the tension in rolling-mill operator's activity, were exposed. Some recommendations on modernization of the existing technology and labor organization were formulated.

Ananalytical model of the organization of the research works devoted to the ergonomic modernization of man-machine systems was developed. Searching and purpose-oriented investigations on the different stages of man-machine system development and exploitation were modelled from the sketchy projection till the exploitation of the system. Theoretical, system analytical and experimental methods were used.

The practical value is the creation of an ergonomic ensuring system of development, exploitation and modernization of difficult men-machine systems and metallurgical production management processes.

\section{REFERENCES}

1. Bedny G. Activity theory: history, research and application. Theoretical Issues in Ergonomics Science. 2010. Vol. 2. P. 168-206.

2. Brito J. About women and work: towards the construction of a female work ergonomics. Designing for every one. L. : Taylor and Francis, 2011. P. $17-22$.

3. Chapanis A. Researcg techniques in human engineering. Baltimore : J. Hopkins University Press, 2012. P. 121-125.

4. Foley J. Fundamentals of Interactive Computer Graphics. Reading : Addisson - Wesley, 2014. P. 73-86. 
5. URL: http://project.ukrinform.ua/company/dniprovskyi_ metalurgiinyi_kombinat_64696.

6. Thu G. The bases of psychology intensification of high-automatical processes under the condition of metalical production (for instance Ukraine, Russia and China). Experimentele Psichologie : Abstract der 45 Tagung experimentell arbeiten der Psychologen. Kiel. 2013. P. 211.

7. Zarakovsky G. The concept of theoretical evaluation of operators' performance derived from activity theory. Theoretical Issues in Ergonomics Science. 2014. Vol. 5. P. 313-337.

Information about the authors: Sheviakov O. V.,

Doctor of Psychological Sciences, Professor, Head of the Department of General Psychology Private Higher Educational Establishment

"Dnipro Humanitarian University"

35, Yermolova str., Dnipro, 49000, Ukraine

Shramko I. A.,

$\mathrm{Ph}$. D. in Psycological Sciences, Associate Professor of the Department of General Psychology Private Higher Educational Establishment "Dnipro Humanitarian University" 35, Yermolova str., Dnipro, 49000, Ukraine 